\title{
Games as Activity: Correcting the Digital Fallacy
}

\author{
Jaakko Stenros and Annika Waern
}

\begin{abstract}
Game studies would benefit from acknowledging that digital games should be studied as a special case of games rather than the other way around. Digital games research tends to look at games as fixed structures or media, largely ignoring the role of the player. Conversely, play and player studies tend to ignore the role of design. We argue that in order to uncover the relationship between game design, game activity and game experience we need to put the game activity in central focus. If games are approached from this perspective, we should study them simultaneously as consciously designed and socially enacted.
\end{abstract}

Key Words: Games, play, activity theory, game design, digital fallacy, enacted experience, consciously designed.

$$
* * * * *
$$

\section{Introduction}

The field of game studies is currently dominated by the study of digital games, and rightly so, due to their economic and rapidly increasing cultural significance in society. To a large extent it seems that currently general game studies are a subsection of digital game studies, not the other way around. Treating digital games as the standard of games is both analytically flawed and intellectually dishonest.

This digital fallacy has had a profound effect of game studies, especially on how the central concept of "game" is framed. Game studies have largely focused on the deconstruction and analysis of the structures and mechanics of games, which has strongly impacted the discussion on what constitutes a game. In game studies, games are most often seen as systems. ${ }^{1}$ This has made the play activity an under-explored area of game studies.

Games are always second order design; game designers create structures that guide player engagement and activity, but their experience is created by their activity with and within the game, and not primarily by the game itself. ${ }^{2}$ It can be argued that games are not complete until they are played. This holds for all games, be it computer games, card games, board games or sports.

In this short paper we argue that looking at games only as systems is detrimental to game studies in the long run. Instead, we argue that studying games as activities should be an important part of game studies, on par with studying the game rules, aesthetics, experiences and interaction models. 


\section{The Digital Fallacy}

Digital games are a special case of games. Though they are a diverse group, they share tendencies towards certain features, features that are not as characteristic of games in general as they are of digital games.

Digital games are largely centred on creating, maintaining and interacting with simulations - probably because, as many researchers have pointed out, computers are excellent tools for just that. ${ }^{3}$ Even those digital games that are not strictly speaking simulations often automate the systemic side of running the game. There is usually no need for a human actor who runs the game such as a gamemaster, a croupier, or a referee, but the facilitation of playing is done by the system. ${ }^{4}$ As these rules are coded, altering them is cumbersome. In digital games it is harder to establish house rules, as changing the system is much more difficult when it is coded than when the facilitation of playing is done by the players themselves. The rules can be changed, and indeed it is standard practice for both the players and the manufacturers to do so. 5

In comparison to non-digital games, digital games are also more often single player games. ${ }^{6}$ The perceived dominance of the single-player games in digital games has been questioned during the last decade by the success of massively multiplayer online worlds, party games with mimetic interfaces, casual games and social games. ${ }^{7}$ Even so, the computational challenge that a computer can offer has created a strong tradition of singleplayer games unrivalled in the history of games.

This emphasis on the single player games and the systemic view as well as the tendency for everything to be documented in digital domains has meant that social play and the sociability surrounding playing has been easily separated from the "game". ${ }^{8}$ It is interesting to contrast this with the words of non-digital game designer Richard Garfield: "it is hard to have a good game experience no matter how good the game is if the metagame is bad." By metagame Garfield means "how the game interfaces outside of itself'; that is, the sociability in and around a game. ${ }^{9}$

Finally, due to the simulation capabilities of computers, many digital games are based on fictional worlds and feature strong narrative structures. ${ }^{10}$ Though there are non-digital games with strong fictional worlds, many digital games emphasize the storyline of the game to the point that its story content is exhausted after one or a few play-throughs. Few non-digital games are these kinds of games of progression.

Viewing games in general through the spectacles of digital games and by generalizing the features presented above creates what we call digital fallacy. Treating digital games as the measure of normalcy severely limits the understanding of those games that do not fit the digital mould. It also tends to 
disregard the activity of play in regards to digital games - and even the agency of the player.

\section{The Systemic View of Games}

It seems that the most oft-cited definitions of games in game studies are the ones supplied by Jesper Juul ${ }^{12}$ and Katie Salen and Eric Zimmerman ${ }^{13}$. Both definitions prioritize the systemic nature of games, something that the older definitions of games rarely do. Indeed, the nature of gameplay as an activity features prominently at least in the definitions of Johan Huizinga, Roger Caillois, Bernard Suits, Clark Abt and even Elliott Avedon and Brian Sutton-Smith. ${ }^{14}$ Researchers who have been writing mostly about digital games do write about games from various angles, cultural, systemic, activity-based, commoditization, but ultimately they tend to favour systemic definitions. The players incorporated in such a system are not the human, social creatures that play games in the real world, but idealized, rational decision makers. ${ }^{15}$

One reason for this emphasis on structure and system instead of player activity is most likely a methodological concern. Studying a game as a system can be perceived as more objective than the study of play activities. In order to access the activity, a game needs to be played. This creates a paradox: the researcher either needs to play the game - which means that she is a participant and her personal experience may be seen as tainting the work - or the researcher needs to study other people who play a game - in which case she only has second hand information on the activity. When games are viewed as systems the activity of playing the game is done just in order to access the underlying system.

This methodological concern is a bit of an ostrich argument. If we embrace the idea that games are second order design, the question can be asked if a game even exists until it is played. Indeed, Laura Ermi and Frans Mäyrä have gone so far as to state that "the essence of a game is rooted in its interactive nature, and there is no game without a player."16 Game studies acknowledge this in practice, if not in theory, as many ludologists consider the playing of the game under scrutiny a pivotal part of the research. ${ }^{17}$

Staffan Björk has advocated that field of game research should be understood as divided into three parts based on the object of study: the game as an artefact, the gamer as an agent, and the gaming as activity. However, this division runs a risk of ignoring the effect a player has on a game. Björk recognized this, and points out that results from the study of playing can be "distilled to design knowledge that can be considered when designing a game system." ${ }^{18}$ We take this a step further and propose that play affects games in a much more direct way. An iterative cycle of redesigning the game by the designer is not needed; players have an impact on the game artifact in 
shaping it through play. Or to put it in another way, there is an overlap between play and design. ${ }^{19}$

A successful approach to play activity study would not only benefit the study of non-digital games. Tanja Sihvonen has argued that the success of The Sims, one of the most successful digital game franchises there is, "cannot be explained by its intrinsic characteristics only"; one must look at the playing of the game. ${ }^{20}$

We propose that a fruitful approach to analysing game activity is from a double perspective, building on the claim that game activities are at the same time both consciously structured and enacted.

\section{Consciously Structured}

All human endeavours are socially situated and embodied. Those features do not differentiate gameplay from, say, working or shopping for groceries. What does mark gameplay apart is that games are activities that are consciously structured in some way. Modern games are consciously designed by a game designer. Many traditional games - as well as some contemporary styles of playing - are products of a long cultural evolution. ${ }^{21}$ However, even these games are subjected to redesign, such as in the design of the play tools and often in the form of house rules governing each particular play situation.

Games are hardly unique as designed activities. On the contrary, it is not uncommon for humans to engage in activities that have been consciously designed. In many cases, it is necessary to design activities to make society function. Designed activities are in fact so common, that we often do not reflect upon the fact that our behaviour has been structured by an external party. When the milk is placed at the very back of the grocery store, we rarely reflect on the fact that the milk run is consciously designed to force us to pass as many shelves as possible - in the hopes that we will pick up a few additional articles. $^{22}$

Some keys to activity design can be found in the architectural distinction between of places, as locations meaningful to humans and locus of human activity - and spaces as the spatial and geometrical setting of that activity. ${ }^{23}$ Human activity is constantly shaped by consciously designed places, from the bathroom to the church. The board game boards, the virtual worlds and the fields, pitches and stadiums play these roles for games. In addition, human activity is often shaped through instruments such as explicit rules and instructions, and a structured pace. We can use the security control of an airport as an archetypical example: the security control is a place, as it is located in physical space and it has a certain architectural design and installations that make us immediately recognize the intended function of the place. At the same time, there is a procedure that people passing through preferably should follow, akin to the interaction methods of a game. Often there is an instruction video running at a monitor in front of the security 
control. The procedure is supported by various installations and finally the conveyer belt that moves our bags sets the pace for the throughput of the security control. Finally, by playing along in the security control ritual, participants get an experience.

On the surface, the difference between the security control and a game seems not to be that large. The core difference lies instead in their purpose: the security control in an airport has several teleological purposes. For players of a game, the purpose of playing is (at least according to the hegemonic ideal) paratelic ${ }^{24}$ : The activity of playing a game is not a means to an end but the end in itself. ${ }^{25}$ In Huizinga's words, the basic conceptualization of play is that it is voluntary and needless ${ }^{26}$ and according to Suits there is an lusory attitude, "the acceptance of constitutive rules just so the activity made possible by such acceptance can occur", at play. ${ }^{27}$

\section{Enacted Experiences}

As discussed previously, game design is realised only as the players engage with the game. Gameplay is thus an enacted experience: what we experience is not 'the game' but a play session, and that session does not exist unless we actively create it.

Just as designed activities, enacted experiences are not uncommon in society. Going to a masquerade, dancing at a wedding, participating in a sauna evening are all examples of social events that have as their main focus to create an experience for the participants. Enacted experiences are also often at least partly designed; just as traditional games they are often supported by consciously designed environments and tools, and sometimes by explicit (house) rules. These tools, environments and rules are designed to heighten and facilitate the experience, but they are not enough to create it: just entering a sauna does not generate a sauna experience; just as swinging a tennis racket does not transmit the experience of a demanding match of tennis.

Two aspects of enacted experiences influence how we should study game activity. The first is that enacted experiences are socially constructed and transferred. One needs to have an expectation of what to experience, in order to fully understand and enjoy it. If you have never been to a sauna or participated in a wine tasting, chances are that you will not appreciate it at all. ${ }^{28}$ Many enacted experiences require a lot of training in order to achieve the full experience. Downhill skiing, lindy-hop dancing, playing the trumpet in a jazz jam session, all are highly rewarding but also difficult activities.

The other aspect is that participants must engage, voluntarily and properly, in order to experience anything at all. This aspect clearly marks games as enacted experiences; almost all game systems can be interpreted and enacted in numerous different ways. The same game can be played in completely different styles, while still adhering to the rules, players may take 
on very different attitudes in different sessions with a game, and sometimes the attitudes will vary also within the same game session.

The expected attitudes of players influence the game played. A particularly illuminating example can be found within role-playing studies. Tabletop role-playing games have inspired a lot of expert hobbyists to write essays and construct models. One of these is the typology that divides playing and game-mastering styles to dramatism, gamism and simulationism. ${ }^{29}$ The first values a satisfying storyline, the second winning over a fair challenge and the third in modelling a world with highest possible fidelity. John Kim describes the modes as 'contracts' that govern both how players are expected to behave, but also what kind of experience the gamemaster is trying to build. Similarly Anders Drachen found that $97 \%$ of people who play Tomb Rider: Underworld, a single player digital game, follow one of four specific play style patterns, ${ }^{30}$ and Nicole Lazzaro identified four distinct types of enjoyment in computer games. ${ }^{31}$

Enacted experiences are often governed by various boundary structures that delimit what constitutes the experience, as well as when and where it is enacted, and who are enacting it. Caillois, Huizinga and Erving Goffman emphasise that games, by design, are set apart from ordinary life. ${ }^{32}$ Game rules and other game structures are important not only in order to structure the actual activity, but also in creating the boundary of the game frame - even if that boundary is porous and subject to renegotiation.

\section{Conclusions}

In this short article, we have deliberately stayed away from any delimiting definition of what a game is, or even, what it means to engage in a game activity. Our analysis frames games as residing in the sweet-spot intersection between designed activities and enacted experiences; they are consciously designed activities that we engage in purely in order to experience something. But games share these properties with activities that we do not consider to be games: bungee-jumping, riding a rollercoaster, and even going to the cinema all belong to this category of human activity. Our framing is not intended to replace the analyses of Huizinga, Caillois, SuttonSmith, Salen and Zimmerman, or Juul, but to complement them; it is intended to provide an alternative perspective. Rather, the fact that it groups games together with numerous other human activities opens up new perspectives for the study of games: if playing a game is similar to bungee-jumping, what can we learn from the design of such paideic activities in designing games? Conversely, what can roller-coaster ride designers learn from game design?

In order to even start to answer such questions, the theoretical perspective presented in this paper has to be deconstructed into various design approaches and modes of engagement, focussing on understanding their interrelationship in the game-as-played activity. 
An example of such a design principle could be openness. This ideal seeks to make games as responsive as possible to player initiative and control. It appears in many different game genres, with slightly different objectives as to what part of the game should be submitted to player control. The reason that it arises could be understood both as a desire to give players more agency than they have in many societal designed activities (such as security controls), and creating room for supporting a range of different enacted experiences. But at the same time, games are not open spaces where anything goes: the rules and goals of the game do structure activity and infuse meaning into enactment. Striking this balance is hardly straight-forward, and studying games from this perspective requires close reading of game-asplayed.

\section{Notes}

${ }^{1}$ J Juul, Half-Real: Video games between real rules and fictional worlds, MIT Press, Cambridge, 2005, p. 36-45. D Myers, 'In Search of a Minimalist Game', in Breaking New Ground: Innovation in Games, Play, Practice and Theory. Proceedings of DiGRA 2009, 1-4 September, Brunel University, West London, UK, 2009. K Salen \& E Zimmerman, Rules of Play, MIT Press, Cambridge, 2004, p. 72-82.

${ }^{2}$ K Salen \& E Zimmerman, p. 168.

${ }^{3}$ E.g. E Aarseth, 'Genre trouble: Narrativist and the art of simulation', in First Person: New Media as Story, Performance and Game, P Harrigan \& N Wardrip-Fruin (eds.), MIT Press, Cambridge, 2004, p. 45-55. E Aarseth, Cybertext: perspectives on ergodic literature, The Johns Hopkins University Press, Baltimore, 1997.

${ }^{4}$ See also J Stenros \& O Sotamaa, 'Commoditization of Helping Players Play: Rise of the Service Paradigm', in Proceedings of Digra 2009

Conference, Breaking New Ground: Innovation in Games, Play, Practice and Theory, 1-4 September, Brunel University, West London, UK, 2009.

${ }^{5}$ S Morris, 'WADs, Bots and Mods: Multiplayer FPS Games as Co-creative Media', in Proceedings of Digital Games Research Conference DiGRA 2003, 4-6 November, University of Utrecht, The Netherlands, 2003.

${ }^{6}$ J Stenros, J Paavilainen \& F Mäyrä, 'The Many Faces of Sociability and Social Play in Games', in Proceedings of $13^{\text {th }}$ International Academic MindTrek Conference: Everyday Life in the Ubiquitous Era, 30 September-2 October, Tampere, Finland, 2009.

J P Zagal, M Nussbaum \& R Rosas, 'A Model to Support the Design of Multiplayer Games', Presence Vol. 9, No. 5, October 2000, 448-462. R Rouse III, Game Design. Theory \& Practice, Wordware Publishing Inc, XXX, 2001. 
${ }^{7}$ J Juul, A Casual Revolution. Reinventing Video Games and Their Players, The MIT Press, Cambridge, 2009, p. 1-2, 145-152. Also J Stenros, J Paavilainen \& F Mäyrä.

${ }^{8}$ J Stenros, J Paavilainen \& F Mäyrä.

${ }^{9}$ R Garfield 2000, "Metagames", in Four Horsemen of Apocalypse. Essays on Roleplaying, J Dietz (ed.), 2000, p. 14-21.

${ }^{10}$ Juul Half-Real, p.1-2, 121-162.

${ }^{11}$ Ibid, p 5.

${ }^{12}$ Ibid, p. 36.

${ }^{13}$ Salen \& Zimmerman, p. 81.

${ }^{14} \mathrm{~J}$ Huizinga, Homo ludens: A study of play element in culture, Beacon Press, Boston, 1955, p. 13. R Caillois, Man, Play and Games, University of Illinois Press, Urbana and Chicago, 2001, p. 9-10. B Suits, 'Construction of a Definition', in The Game Design Reader. A Rules of Play Anthology, K Salen, \& E Zimmerman (eds.), Massachusetts, MIT Press, 2006, p. 172-191. C C Abt, Serious games, Viking Press, New York, 1970, p. 6-7. E M Avedon \& B Sutton-Smith, Introduction to The Study of Games, E M Avedon \& B Sutton-Smith (eds.), John Wiley \& Sons Inc, New York, 1971, p. 1-8.

${ }^{15}$ S Björk, 'Games, Gamers and Gaming. Understanding Game Reseach', in Proceedings of 12th International MindTrek Conference: Entertainment and Media in the Ubiquitous Era, A Lugmayr, F Mäyrä, H Franssila \& K Lietsala (eds.), Tampere, Finland, October 2008, p. 64-68.

${ }^{16}$ L Ermi \& F Mäyrä, 'Fundamental components of the gameplay experience: Analysing immersion', in Proceedings of Digra 2005, 2005.

${ }^{17}$ E Aarseth, 'Playing Research: Methodological Approaches to Game Analysis', in Proceedings of the $5^{\text {th }}$ Digital Arts \& Culture Conference. Melbourne, Australia, 2003. J Suominen, R Koskimaa, F Mäyrä \& O Sotamaa, 'Johdanto', in Pelitutkimuksen Vuosikirja 2009, J Suominen, R Koskimaa, F Mäyrä \& O Sotamaa (eds.), www.pelitutkimus.fi/vuosikirja2009 (ref. 25.5.2010), 2009. M Montola, 'Social Constructionism for Ludology', presented at Games Research Methods seminar, 8-9 April, University of Tampere, Finland, 2010.

${ }^{18}$ Björk, p. 64-68.

${ }^{19}$ O Sotamaa, The Player's Game. Towards Understanding Player Production among Computer Game Cultures. Doctoral Dissertation, Department of Journalism and Mass Communication, University of Tampere, 2009 , p. 82.

${ }^{20}$ T Sihvonen, Players Unleashed! Modding The Sims and the Culture of Gaming, Doctoral Dissertation, University of Turku, 2009, p. 6.

${ }^{21}$ D Parlett, The Oxford History of Board Games, Oxford University Press, Great Britain,1999. 
${ }^{22} \mathrm{P}$ Underhill, Why we buy: The science of shopping, Updated Revised Edition, Simon \& Schuster, 2008.

${ }^{23}$ Y-F Tuan, Space and Place: The Perspective of Experience, University Of Minnesota Press, XXX, 2001. Unwin, S., Analysing Architecture. $3^{\text {rd }}$ edition. Routledge, 2009, p. 28-29.

${ }^{24}$ M J Apter 'A structural-phenomenology of play', in Adult Play: A Reversal Theory Approach, J.H. Kerr \& M.J. Apter (Eds.), Swets \& Zeitlinger,

Amsterdam, 1991.

${ }^{25}$ See also Abt, p. 5.

${ }^{26}$ Huizinga, p. 7-8.

${ }^{27}$ Suits.

${ }^{28}$ See also H S Becker, 'Becoming a marihuana user', American Journal of Sociology, Vol. 59, No. 3, 1953, pp. 235-242

${ }^{29}$ J H Kim, 'The Threefold Model FAQ', (ref. 25.5.2010), www.darkshire.net/ jhkim/rpg/theory/threefold/faq_v1.html, 2003. See also E C Boss, 'Key Concepts in Forge Theory', in Playground Worlds. Creating and Evaluating Experiences of Role-Playing, M Montola \& $\mathrm{J}$ Stenros (Eds.), Ropecon ry, Jyväskylä, 2008.

${ }^{30}$ A Drachen, 'Patterns of play', presentation at Ludic Aspects of Everyday Life seminar, IT University of Copenhagen, 11 January, 2010.

${ }^{31} \mathrm{~N}$ Lazarro 'Why we play games: Four keys to more emotion without story'. XeoDesign White paper,

http://www.xeodesign.com/xeodesign_whyweplaygames.pdf

${ }^{32}$ Huizinga, p. 10. Caillois, p. 9. E Goffman Encounters: Two Studies in the Sociology of Interaction, Bobbs-Merrill, Indianapolis, 1961, p.65-66. E Goffman, Frame Analysis. An Essay on the Organization of Experience, Northeastern University Press, Boston, 1974, p.40-47.

\section{Bibliography}

Aarseth, E., Cybertext: perspectives on ergodic literature. The Johns Hopkins University Press, 1997.

Aarseth, E., 'Playing Research: Methodological Approaches to Game Analysis'. Proceedings of the $5^{\text {th }}$ Digital Arts \& Culture Conference. Melbourne, Australia, 2003.

Aarseth, E., 'Genre trouble: Narrativist and the art of simulation', First Person: New Media as Story, Performance and Game, P Harrigan \& N Wardrip-Fruin (eds.), MIT Press, Cambridge, 2004, p. 45-55.

Abt, C.C., Serious games. Viking Press, New York, 1970. 
Apter, M.J., 'A structural-phenomenology of play'. Adult Play: A Reversal Theory Approach, J.H. Kerr \& M.J. Apter (Eds.), Swets \& Zeitlinger, Amsterdam, 1991.

Avedon, E.M. \& Sutton-Smith, B., Introduction to The Study of Games, E M Avedon \& B Sutton-Smith (eds.), John Wiley \& Sons Inc, New York, 1971.

Becker, H.S., 'Becoming a Marihuana User'. American Journal of Sociology, Vol. 59, No. 3, 1953, pp. 235-242.

Boss, E.C., 'Key Concepts in Forge Theory', Playground Worlds. Creating and Evaluating Experiences of Role-Playing, M Montola \& J Stenros (Eds.), Ropecon ry, Jyväskylä, 2008.

Björk, S., 'Games, Gamers and Gaming. Understanding Game Reseach'. Proceedings of 12th International MindTrek Conference: Entertainment and Media in the Ubiquitous Era, A Lugmayr, F Mäyrä, H Franssila \& K Lietsala (eds.), Tampere, Finland, October 2008, p. 64-68.

Caillois, R., Man, Play and Games. University of Illinois Press, Urbana and Chicago, 2001.

Drachen, A., 'Patterns of Play', presentation at Ludic Aspects of Everyday Life seminar, IT University of Copenhagen, 11 January, 2010.

Garfield R., 'Metagames'. Four Horsemen of Apocalypse. Essays on Roleplaying, Dietz, J. (Ed.), Jolly Roger Games, Charleston, 2000.

Ermi L. and Mäyrä, F., 'Fundamental components of the gameplay experience: Analysing immersion’. Proceedings of Digra 2005, 2005. Goffman, E., Encounters: Two Studies in the Sociology of Interaction. Bobbs-Merrill, Indianapolis, 1961.

Goffman, E., Frame Analysis. An Essay on the Organization of Experience. Northeastern University Press, Boston, 1974.

Huizinga, J., Homo ludens: A study of play element in culture. Beacon Press, Boston, 1955.

Juul, J., Half-Real: Video games between real rules and fictional worlds. MIT Press, Cambridge, 2005.

Juul, J., A Casual Revolution. Reinventing Video Games and Their Players. The MIT Press, Cambridge, 2009.

Kim, J.H., "The Threefold Model FAQ."

www.darkshire.net/ jhkim/rpg/theory/threefold/faq_v1.html. (ref. 25.5.2010), 2003.

Lazarro, N., 'Why we play games: Four keys to more emotion without story'. XeoDesign White paper.

http://www.xeodesign.com/xeodesign_whyweplaygames.pdf Montola, M., 'Social Constructionism for Ludology', Games Research Methods seminar, 8-9 April, University of Tampere, Finland, 2010. 
Morris, S., 'WADs, Bots and Mods: Multiplayer FPS Games as Co-creative Media'. Proceedings of Digital Games Research Conference 2003, 4-6 November, University of Utrecht, The Netherlands, 2003.

Myers, D., 'In Search of a Minimalist Game', Breaking New Ground: Innovation in Games, Play, Practice and Theory. Proceedings of DiGRA 2009, 1-4 September, Brunel University, West London, UK, 2009.

Parlett, D., The Oxford History of Board Games, Oxford University Press, Great Britain, 1999.

Rouse III, R., Game Design. Theory \& Practice, Wordware Publishing Inc, XXX, 2001

Salen, K. and Zimmerman, E., Rules of Play. MIT Press, Cambridge, 2004. Sihvonen, T., Players Unleashed! Modding The Sims and the Culture of Gaming. Doctoral Dissertation, University of Turku, 2009.

Sotamaa, O., The Player's Game. Towards Understanding Player Production among Computer Game Cultures. Doctoral Dissertation, Department of Journalism and Mass Communication, University of Tampere, 2009. Stenros, J. \& Sotamaa, O., 'Commoditization of Helping Players Play: Rise of the Service Paradigm'. Proceedings of Digra 2009 Conference, Breaking New Ground: Innovation in Games, Play, Practice and Theory, 1-4 September, Brunel University, West London, UK, 2009. Stenros, J., Paavilainen, J. and Mäyrä, F., 'The many faces of sociability and social play in games". Proceedings of MindTrek 2009, Tampere, Finland, 2009.

Suits, B., 'Construction of a Definition'. The Game Design Reader. A Rules of Play Anthology, K Salen, \& E Zimmerman (eds.), Massachusetts, MIT Press, 2006, p. 172-191.

Suominen, J., Koskimaa, R., Mäyrä, F. \& Sotamaa, O., 'Johdanto'. Pelitutkimuksen Vuosikirja 2009, J Suominen, R Koskimaa, F Mäyrä \& O Sotamaa (eds.), www.pelitutkimus.fi/vuosikirja-2009 (ref. 25.5.2010), 2009. Tuan, Y-F, Space and Place: The Perspective of Experience, University Of Minnesota Press, XXX, 2001.

Underhill,P., Why we buy: The science of shopping, Updated Revised Edition. Simon \& Schuster, 2008.

Unwin, S., Analysing Architecture. $3^{\text {rd }}$ edition. Routledge, 2009.

Zagal, J.P., Nussbaum, M. and Rosas, R., 'A model to support the design of multiplayer games'. Presence Vol. 9, No. 5, October 2000, 448-462. 